\title{
Optimization and Simulation of Double Wishbone Suspension of Car Based on Vibration comfort
}

\author{
Lifang Yang ${ }^{1,}$, , Hongtao Zheng ${ }^{1, b}$ \\ ${ }^{1}$ Department of Industrial Design, Harbin Institute of Technology, Harbin 150001, China \\ ayanglifang@hit.edu.cn, bhtzphoenix@gmail.com
}

\begin{abstract}
Keywords: Vibration comfort, Double-wishbone independent suspension, Duplex hydraulic shock absorber, 3D Modeling and Simulation.

Abstract: The riding comfort is the essential pursuit for car option and the car suspension system contributes the most effect to car riding comfort. Hence, research of suspension system has become one of the most imortant issues for vehicle riding comfort. In the paper, The study aims to design develop a new suspension system, combined with the design requirements of the automotive suspension system and analysis of the advantages and disadvantages of system and the solutions to improve vibration comfort are proposed, the detailed parameters for guiding structure and shock absorbers are confirmed. Then using MATLAB and 3D technology, the rationality of the solutions are simulated and tested. The solutions of double-wishbone independent suspension improves the lifetime of ball pin structure and ensures the whole suspension system more stable and impact resistant.
\end{abstract}

\section{Introduction}

Car has become a part of people's daily lives and the riding comfort is the most important pursuit for car option. People pay more attention to dynamic and comfort performance of the car, which comfort become one of the indicators of consumer concern. Perspective of comfort, in addition to the hardness of the seat or vehicle comfort spatial structure of the layout, the greatest impact is from support, cushioning, damping effect of the suspension system, which determines stability control and affects the car's riding comfort at high speed running.

Japanese scholars H.suzuki researchers explored the Japanese vehicle operation comfort trends, developed and introduced based on 1,502,631 comfort level index RcL (Ridingcomfortlevel). Fellow South Korean scholars Y.G.Kim details several evaluation methods sperling stationary targets, 1,502,631 evaluation methods, UIC513 evaluation methods, and to study the relationship between the above evaluation method. Professor Pu Qianhui based on dynamic performance tests analyzed the comfortable degree of vehicle runtime [1].

Most modern cars are equipped with passive suspension, commonly used Double wishbone, McPherson, Dual-Link, Multi-Link, Trailing Arm Suspension, etc.. With the advent of Semi-Active Suspension and Active Suspension, the comfort is better improved. Active suspension can be performed in real time by controlling the operation of the ECU, deal with complex road body is still very stable, low noise, steering and body to maintain the relative level of braking. But as it too perplexed, poor reliability, high energy consumption, the production process is complicated and high cost so that it failed to cyclopedic used $[2,3]$.

\section{Structural Optimization Program of Suspension System}

According to the strengths and weaknesses which the structural characteristics of the double wishbone can modify structure parameters. Cancel the original unequal-length A-arm structure, replaced by an independent Axis cervical stent BC, its and high-strength sheet metal connections $\mathrm{CF}$ original composition upper wishbone D and damper support MN. To make it modular, and the original structure to a multi-degree of freedom spatial orientation is solely responsible for the dual structure of the tire bouncing up and down and side to side. Distribution structure is more reasonable to change the connection type original ball hinge, and overall stiffness of the more stable, as shown in Fig.1. 


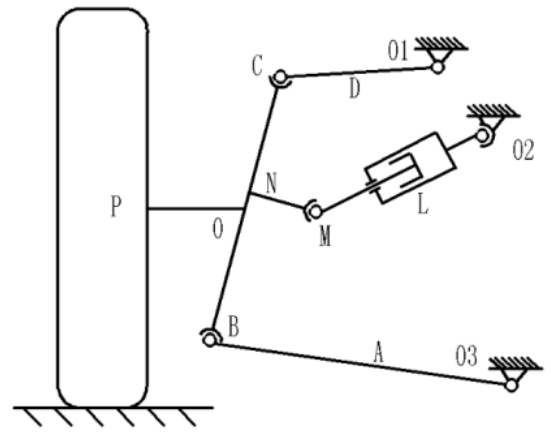

(a)

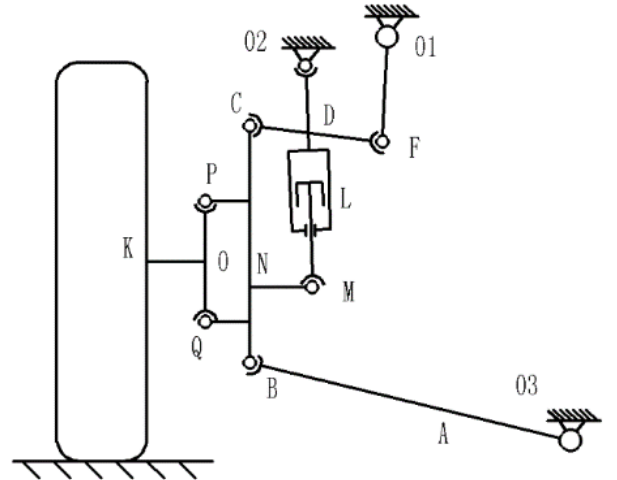

(b)

Fig 1. a) Optimize the structure diagram of the front double wishbone system b) Chart optimized double wishbone system.

\section{Results and Discussion}

As shown in Fig. 2. Extension cord to connect from the intersection of the upper and lower arm hinged pair obtained pole $\mathrm{P}$, which can be calculated. The point $\mathrm{P}$ and $\mathrm{N}$ wheel ground connection can be obtained by tilting the center point $\mathrm{W}$ car axis. The calculation shows that the suspension roll center height is $h_{w}=288.5 \mathrm{~mm}[4,6]$. Knuckle spatial localization parameters selected by the design criteria for the offset distance $-10 \mathrm{~mm}$. In summary, the knuckle spatial orientation parameters as shown in Table 1.

Table 1 The targeting parameters

\begin{tabular}{|c|c|}
\hline Variable & Parameter \\
\hline Front Toe & $1^{\circ}$ \\
\hline Camber angle & $0^{\circ} 30$ \\
\hline caster angle & $3^{\circ}$ \\
\hline kingpin inclination & $7^{\circ}$ \\
\hline Steering pin offset distance & $-10 \mathrm{~mm}$ \\
\hline wheel base changes & $20 \mathrm{~mm}$ \\
\hline
\end{tabular}

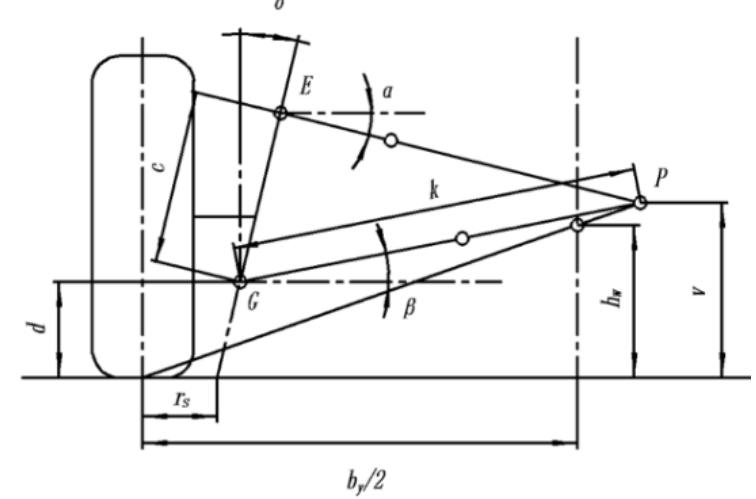

(a)

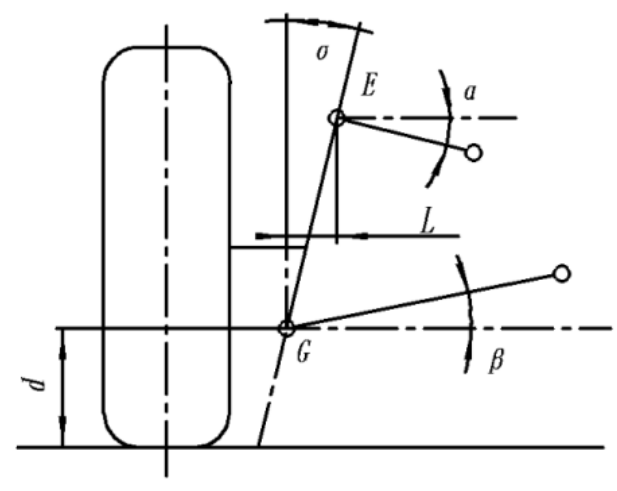

(b)

Fig 2. a) Determination of the roll center $\mathrm{W}$ b) Kingpin steering angle and offset distance

Suspension coil spring material is selected 60Si2MnA (quenching and tempering silicon-manganese), belong to I load spring, GB4361C, automobile suspension spring material. The following table shows the overall parameters of the spring, as shown in Table 2. 
Table 2 Suspension coil spring parameters

\begin{tabular}{lc}
\hline & Construction \\
\hline External diameter & Parameter \\
Internal diameter & $110 \mathrm{~mm}$ \\
Effective and total number of cycles & $90 \mathrm{~mm}$ \\
Deformation amount & $7 \mathrm{n} 、 9 \mathrm{n}$ \\
Initial pitch & $77.64 \mathrm{~mm}$ \\
Free height & $52.72 \mathrm{~mm}$ \\
Actual pitch & $454.09 \mathrm{~mm}$ \\
Spiral rise angle & $52.86 \mathrm{~mm}$ \\
Steel wire length & 8.65 \\
\hline
\end{tabular}

Characteristics of the shock absorber can be obtained by variation of the graph to describe the size of the valve opening force of architecture and a direct impact on the shape of the curve, a vital factor in the design of the valve system is the influence of the flow in the cylinder oil density, oil heat in the density of the liquid to be generated far exceeds the oil flow, so almost negligible effect of temperature on the damper characteristics.

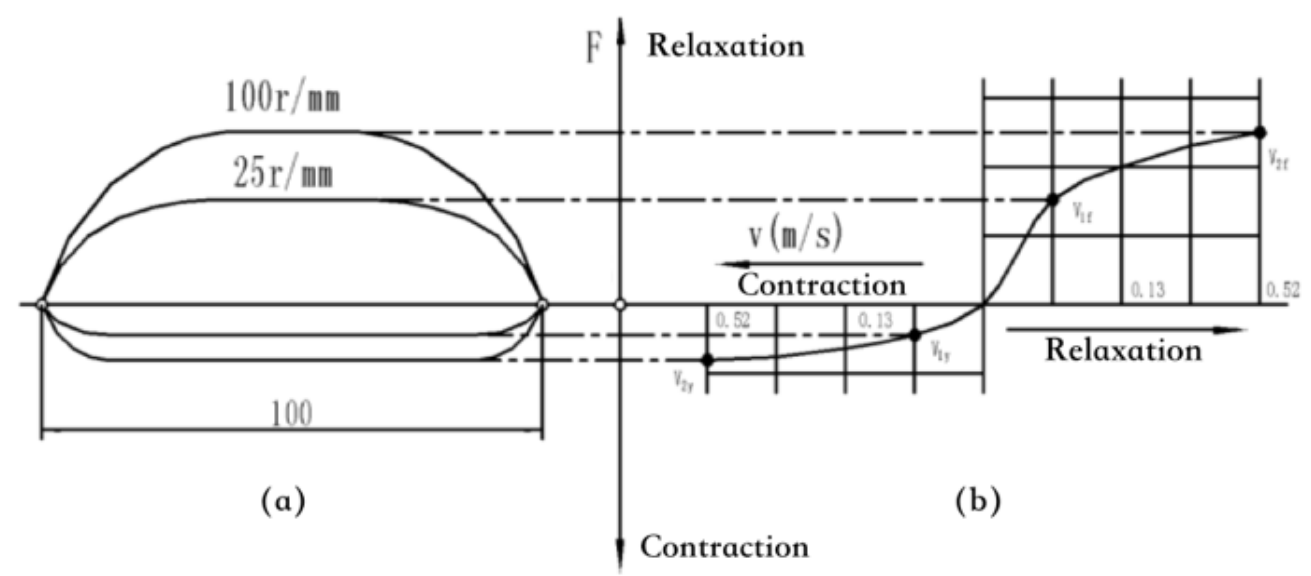

$\begin{array}{ll}\text { (a) Resistance - displacement characteristics } & \text { (b) Resistance - speed characteristic }\end{array}$

Fig 3. Shock absorber characteristic diagram

As show in Fig. 3. A linear relationship between $\mathrm{F}$ and $\mathrm{v}$, known as linear combination ratio characteristics. The resistance - speed characteristics can be regarded as an approximate four straight line segments, when before unloading valve open its segment on the slope of the damping, compression damping figure shows often done in less than damping factor [5]. Damping characteristics can be used to calculate the body structure and optimization of the body structure design.

Duplex hydraulic shock absorber to match the placement, which design chosen $\alpha=3^{\circ}$. Range of double hydraulic shock absorber damping is $\varphi_{\mathrm{v}}=(0.25 \sim 0.5) \varphi_{\mathrm{s}}[7]$, this paper takes the relative damping factor $\varphi=0.35$. Damping coefficient is $1748.34[8,9]$. As show in Table 3, it is duplex hydraulic damper member structure size optimization.

Table 3 Shock Absorber overall parameters

\begin{tabular}{lc}
\hline \multicolumn{1}{c}{ Construction } & Parameter \\
\hline The cylinder diameter D & $45 \mathrm{~mm}$ \\
Primaries cylinder wall thickness & $2 \mathrm{~mm}$ \\
Piston stroke $S$ & $180 \mathrm{~mm}$ \\
Initial length & $300 \mathrm{~mm}$ \\
The minimum length of the guide & $24 \mathrm{~mm}$ \\
Bottom of the seat diameter & $2 \mathrm{~mm}$ \\
Seat bottom hole length & $6.5 \mathrm{~mm}$ \\
\hline
\end{tabular}

Suspension system mounting assembly is shown in Fig.4. 


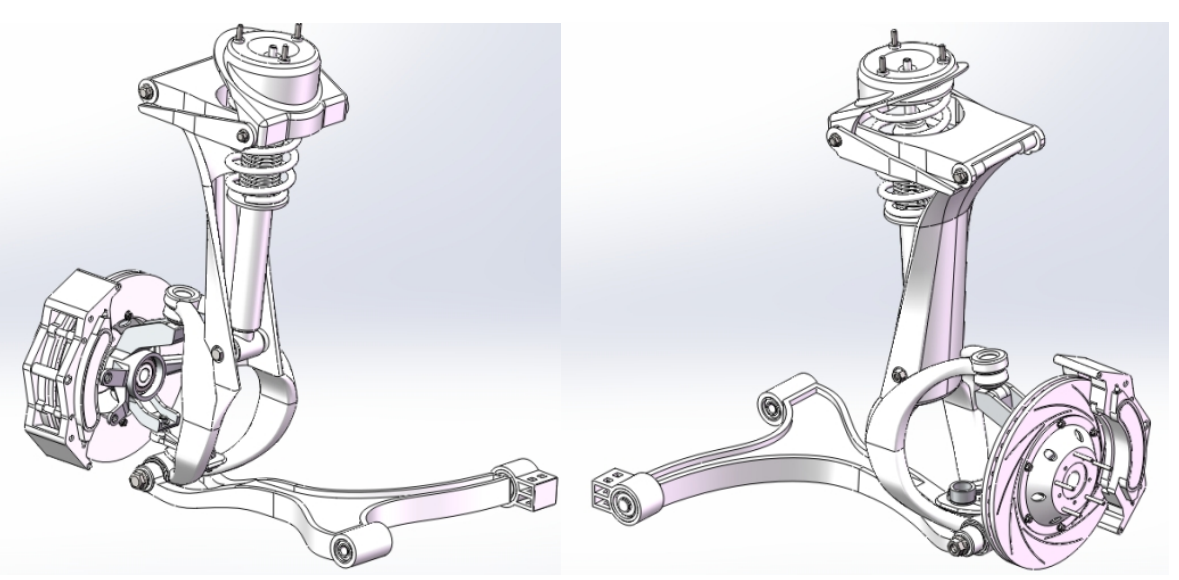

Fig 4. Suspension system assembly

\section{Simulation and Calibration}

According to the mechanical theorems, which can obtain Vibration Differential Equations [10].

$$
\begin{aligned}
& M(\mathcal{L}-k(Z-s)=0 \\
& m(Z)-k(Z-s)+k_{t} s=k_{t} q
\end{aligned}
$$

This formula: $\mathrm{M}$ is the sprung mass; $\mathrm{m}$ non-sprung mass; $\mathrm{k}$ is the stiffness of the suspension synthesis; $\mathrm{c}$ is equivalent suspension damping; $\mathrm{k}_{\mathrm{t}}$ is tire width; $\mathrm{Z}$ is sprung mass; $\mathrm{s}$ non-sprung mass $\mathrm{m}$ of vertical displacement $(\mathrm{m})$; $\mathrm{q}$ is the traffic characteristic value $(\mathrm{m})$, that is the road to the actual body vibration excitation.

In this case the general solution of differential equations is

$$
Z=A e^{-n t} \sin \left(\sqrt{\omega_{0}^{2}-b^{2} t}+a\right)
$$

Use MATLAB can draw the following acceleration amplitude-frequency characteristic curve and dynamic deflection amplitude as shown in Fig. 5.

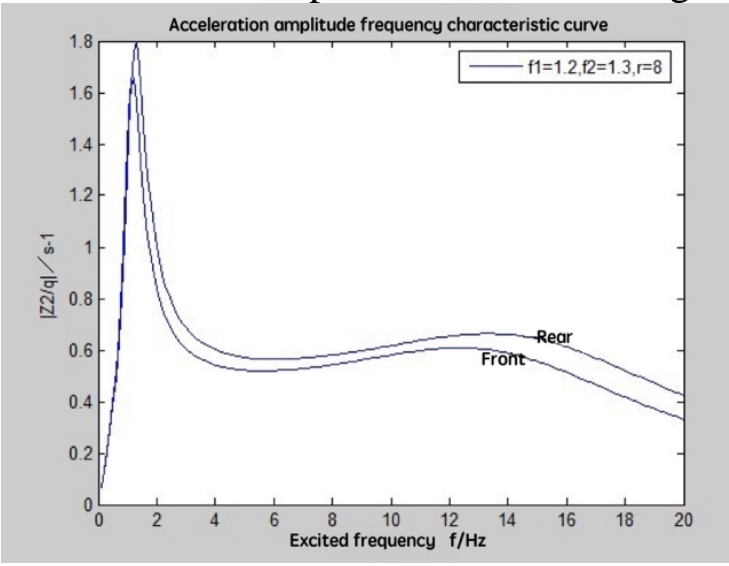

(a)

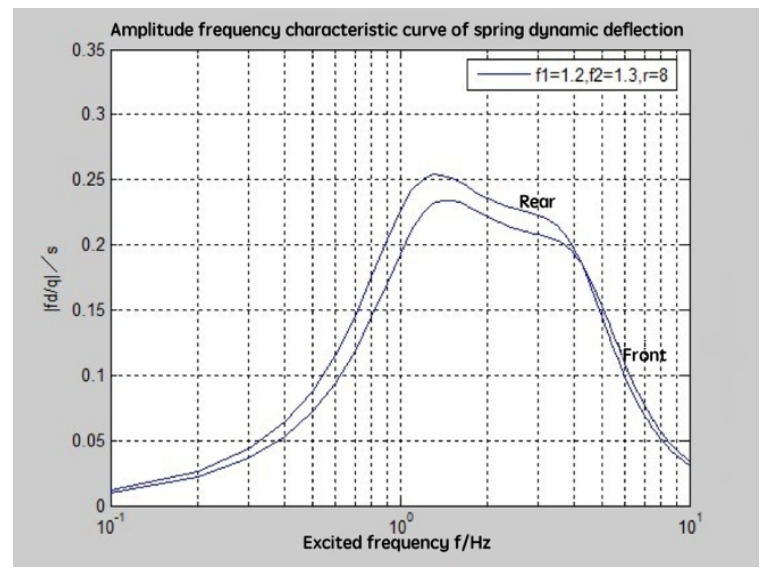

(b)

Fig 5. a) Acceleration amplitude-frequency characteristic curve b) Dynamic deflection amplitude -frequency characteristic curve

From the figure, when the body resonance damping ratio increases and decreases the amplitude-frequency, resonance peak in the curve of the two intervals, increasing its amplitude-frequency damping ratio increases, when $f=f_{t}$, the system appears resonance peak, when $f>f_{t}$, the slope of the amplitude-frequency characteristics with a certain attenuation, damping ratio decreases, and the effect of high-frequency resonance zone opposite. In summary, the damping ratio take 0.2 to 0.4 is reasonable [11].

It is a schematic view of the stroke stop and mathematical model of the frequency response [1] is: 


$$
\left|\frac{f_{d}}{\phi}\right|=\frac{\gamma}{\omega} \lambda^{2}\left[\frac{1}{\Delta}\right]^{\frac{1}{2}}
$$

The suspension system is a low-pass filter for high-frequency attenuation of the displacement body is $\mathrm{Z}$; high-pass filter for dynamic deflection $f_{d}$ is the low frequency input attenuation. Damping ratio $\theta$

of $\left|f_{d} / q\right|$ only work in the resonance region, and when $\zeta=0.5$ no longer reflect the peak. Damping ratio $\theta$ value is inversely proportional to frequency and amplitude, as shown in Fig.8. The figure shows that when the damping is 0.28 , the results are consistent with ISO 02631-1: 1997 (E) standard, the standard of damping ratio at $0.2-0.4$ is more suitable.

\section{Conclusion}

In the paper, through research on the double wishbone suspension, the suspension of car is optimized and improved and thus the control and stability of the vehicle are improved in the riding process.

(1) Improvement of upper and lower arm mechanism and introduction of independent axis neck support, thus the structure of multi freedom spatial structure of the double wishbone suspension is changed to double structure of independently steering and jumping.

(2) The original ball head pin hinge is changed to rubber alloy ball pin hinge and fundamentally improve the drawbacks of the ball head pin and the suspension can work in a more hostile environment, have excellent performance of impact resistance, extended service life.

(3) The spatial positioning parameters are optimized and the spatial layout of the suspension guide mechanism is compressed. Thus the overall weight of the suspension is reduced, the spring performance is optimized and the nature of manipulative and smooth are improved.

The double wishbone suspension research, optimization, simulation, evaluation and results of the paper are based on rigid body vehicle model, also the process can be conducted on flexible vehicle model.

If based on flexible vehicle model, the amplitude and frequency characteristic curves of acceleration may appear multiple resonance peaks. Maybe with gradually increasing acceleration, the index of vibration comfort may decline, all these can be further studied by simulation model.

\section{References}

[1] Ziyaeifar M, Vehicle System Dynamics, Nature Vol. 43 (2011), p. 771-794

[2] R. H. Tian, Z. X. Wang, Mechanical Engineers, Vol. 3 (2006), p. 100

[3] Q. Zhang, L. S. Transactions of The Chinese Society of Agricultural Machinery, Vol. 36 (2005), p. 124- 126

[4] L. S. Zhou, Automotive Engineering, Vol. 26 (2004), p. 697

[5] C. C. Zhou, Transactions of The Chinese Society of Agricultural Machinery, Vol. 22 (2006). p. 121

[6] J. M. Shun, Journal of Heilongjiang Institute of Technology, Vol. 15 (2001), p. 58

[7] Isobe O, T Kawabe, Y Watanabe, Y Miyasato and S Hanba. On Advanced Vehicle Control, Aachen, Germany, Vol. 46 (1995), p. 32

[8] C. C. Zhou, Journal of Beijing Institute of Technology, Vol. 1 (2007), p. 165

[9] G. Priyandoko, M.Mailah, H. Jamaluddin, Mechanical Systems and Dignal Processing, Mechanical Systems and Dignal Processing, England, Vol. 23 (2002), p. 42

[10] X. Y. Zhang, Identification and Control, Nordic, (2002). 